\title{
Gut-brain signaling in energy homeostasis: the unexpected role of microbiota-derived succinate
}

\author{
Filipe de Vadder1,2,3 and Gilles Mithieux ${ }^{1,2,3}$ \\ 'Institut National de la Santé et de la Recherche Médicale, U1213, Lyon, France \\ 2Université Lyon 1, Villeurbanne, France \\ 3Université de Lyon, Lyon, France \\ Correspondence should be addressed to G Mithieux: gilles.mithieux@inserm.fr
}

\section{Abstract}

In the context of the obesity epidemic, dietary fibers that are found essentially in fruit and vegetables attract more and more attention, since they exert numerous metabolic benefits resulting in the moderation of body weight. Short-chain fatty acids, such as propionate and butyrate, produced through their fermentation by the intestinal microbiota, have long been thought to be the mediators of these benefits. In fact, propionate and butyrate were recently shown to activate intestinal gluconeogenesis, a function exerting metabolic benefits via its capacity of signaling to the brain by gastrointestinal nerves. Recently, succinate, the precursor of propionate in the bacterial metabolism, has also been shown to exert signaling properties, including the activation of intestinal gluconeogenesis.

\author{
Key Words \\ - gut microbiota \\ - succinate \\ - short-chain fatty acid \\ - intestinal gluconeogenesis \\ - gut-brain axis \\ - glucose metabolism
}

Journal of Endocrinology (2018) 236, R105-R108

\section{Introduction}

The worldwide increase in obesity and associated illnesses such as type 2 diabetes has urged the scientific community to improve our understanding of the mechanisms underlying energy homeostasis. A welldocumented area relates to the hormonal signals that the gut releases in blood in response to nutrient assimilation and which modulate hunger sensations and glucose homeostasis, such as cholecystokinin and glucagon-like peptide 1, a set of processes referred to as the gut-brain axis. An increasingly popular field of investigation relates to the gut microbiota, residing mainly in the distal gut. The genetic composition of the gut microbiota is altered in obesity and metabolic diseases, which has led to the idea that the microbiota changes could have a role in the regulation of host metabolism. It is noteworthy that various macronutrients, such as dietary protein, are also able to influence the host metabolism, and especially hunger and glucose control. In this context, the possible role of dietary fiber, via its fermentation by the gut microbiota, currently attracts more and more interest.

\section{Effects of dietary fiber on microbiota and host metabolism}

Dietary fiber corresponds to oligosaccharides that cannot be metabolized by the host intestinal enzymes, but are metabolized by the microbiota in the cecum and colon (Macfarlane \& Macfarlane 2003). The major products from the microbial fermentation are short-chain fatty acids (SCFAs), namely acetate, propionate and butyrate (Cummings et al. 1987). These metabolites can then be efficiently used by the intestinal mucosa and/or next host metabolism. The concentration of SCFAs varies along the length of the gut, with the highest concentrations in the proximal colon. For a thorough review on SCFA 
production and physiological concentrations refer to study by Koh and coworkers (Koh et al. 2016).

Among dietary fiber, fructans (or fructooligosaccharides, FOS) have been studied extensively. Some bacteria, such as Bifidobacterium spp., express the enzyme $\beta$-fructofuranosidase and are able to break down the oligosaccharides. The presence of FOS in the intestine stimulates the development of such bacteria. For example, a remarkable increase in Bifidobacterium spp. was observed in diabetic mice that were fed inulin-type fructans (Cani et al. 2007, 2009, Dewulf et al. 2011). The increase in Bifidobacteria was inversely correlated to the development of adiposity and glucose intolerance (Cani et al. 2007). Moreover, fructan supplementation induces an increase of GLP-1-producing L-cells in the colon and jejunum, which could be at the origin of the metabolic benefits linked to GLP-1 (Cani et al. 2006, Delzenne et al. 2007).

\section{Short-chain fatty acids are a link in the metabolic benefits of dietary fiber}

It has long been thought that the production of SCFAs from dietary fiber by the gut microbiota could account for the beneficial effects of dietary fiber (for a review, see Koh et al. 2016). For instance, mice and rats fed a butyrateenriched diet have increased thermogenesis and energy expenditure (Gao et al. 2009), as well as improved glucose tolerance (Lin et al. 2012, De Vadder et al. 2014). Human studies using acute and long-term administration of the inulin-propionate ester, which can be metabolized to propionate in the colon, have shown that GLP-1 and PYY secretion were increased, concomitantly with reduced calorie intake and weight gain (Chambers et al. 2015).

Besides, we previously showed that the delivery of glucose in the portal vein and its neural sensing by the sodium-coupled glucose co-transporter 3 (SGLT3) in the vein walls and subsequent signaling to the brain initiates a set of events, generally referred to as the 'portal glucose signal'. This signal promotes various metabolic benefits, including decreased food intake and improved insulin sensitivity and glucose control (Delaere et al. 2012, see e.g. Soty et al. 2017 for a review). We also established that intestinal gluconeogenesis (IGN), a gut function-releasing glucose upstream of the portal nervous system, could activate the portal glucose signal and its associated benefits (Mithieux et al. 2005, Troy et al. 2008). It is noteworthy that we could then show that the activation of IGN by butyrate and propionate could in fact account for by the beneficial metabolic effects of dietary fibers (De Vadder et al. 2014). This provided a key mechanistic insight in the way by which the microbiota function may influence host metabolism.

\section{Microbiota-derived succinate}

Succinate is a major intermediary in the citric acid cycle, where it stands between succinyl-coA and fumarate. In the gut, the microbiota can also produce important amounts of succinate, especially from fermentation of polysaccharides and oligosaccharides. Microbiota-produced succinate is classically described as an intermediate in propionate synthesis and is supposed to accumulate to a lesser extent because of its conversion in propionate (Cummings et al. 1987). However, a marked increase in cecal succinate concentration was reported upon dietary fiber feeding in mice (De Vadder et al. 2016). Human studies have shown that succinate ranges in a concentration from 1 to $3 \mathrm{mM}$ in intestinal content and feces, i.e. 2-4\% of total organic anions in feces (Meijer-Severs \& van Santen 1987). In mice, its cecal concentration is greatly increased by feeding dietary fiber, especially whether fiber is given in supplementation of a high-fat diet (Jakobsdottir et al. 2013, Everard et al. 2014, Zhong et al. 2015, De Vadder et al. 2016). The major producers of succinate in the gut are bacteria from the phylum Bacteroidetes (Miller \& Wolin 1979). Succinate has been shown to activate dendritic cells (Rubic et al. 2008), thus acting as a modulator of intestinal inflammation. In line with this idea, an increase in succinate, induced by a diet rich in polyphenols, blocks growth and proliferation of colon cancer cells, as well as angiogenesis (Haraguchi et al. 2014). Furthermore, colonization of conventionally raised mice with the succinate-producing bacterium Prevotella copri contributes to an improvement in glucose control, through succinate-dependent and -independent mechanisms (Kovatcheva-Datchary et al. 2015, De Vadder et al. 2016).

A putative receptor for succinate was discovered in 2004, named GPR91 (He et al. 2004). While in vitro and in silico studies have suggested that GPR91 can also bind other carboxylic acids, its affinity for them was much lower than that for succinate $\left(\mathrm{EC}_{50}\right.$ from 20 to $\left.50 \mu \mathrm{M}\right)$, suggesting that succinate is the endogenous ligand of GPR91. While GPR91 is widely expressed in the body, plasma concentrations of succinate vary from 2 to $20 \mu \mathrm{M}$ in mice and humans (Kushnir et al. 2001, Sadagopan et al. 2007), suggesting that, under physiological conditions, activation of GPR91 by succinate might only be relevant in the gut lumen. 


\begin{tabular}{l|l|l|l|l|}
$\begin{array}{l}\text { Journal of } \\
\text { Endocrinology }\end{array}$ & F de Vadder and G Mithieux & $\begin{array}{l}\text { Gut-brain glucose signaling by } \\
\text { succinate }\end{array}$ & $\mathbf{2 3 6 : 2}$ & $\mathbf{R 1 0 7}$ \\
\hline
\end{tabular}

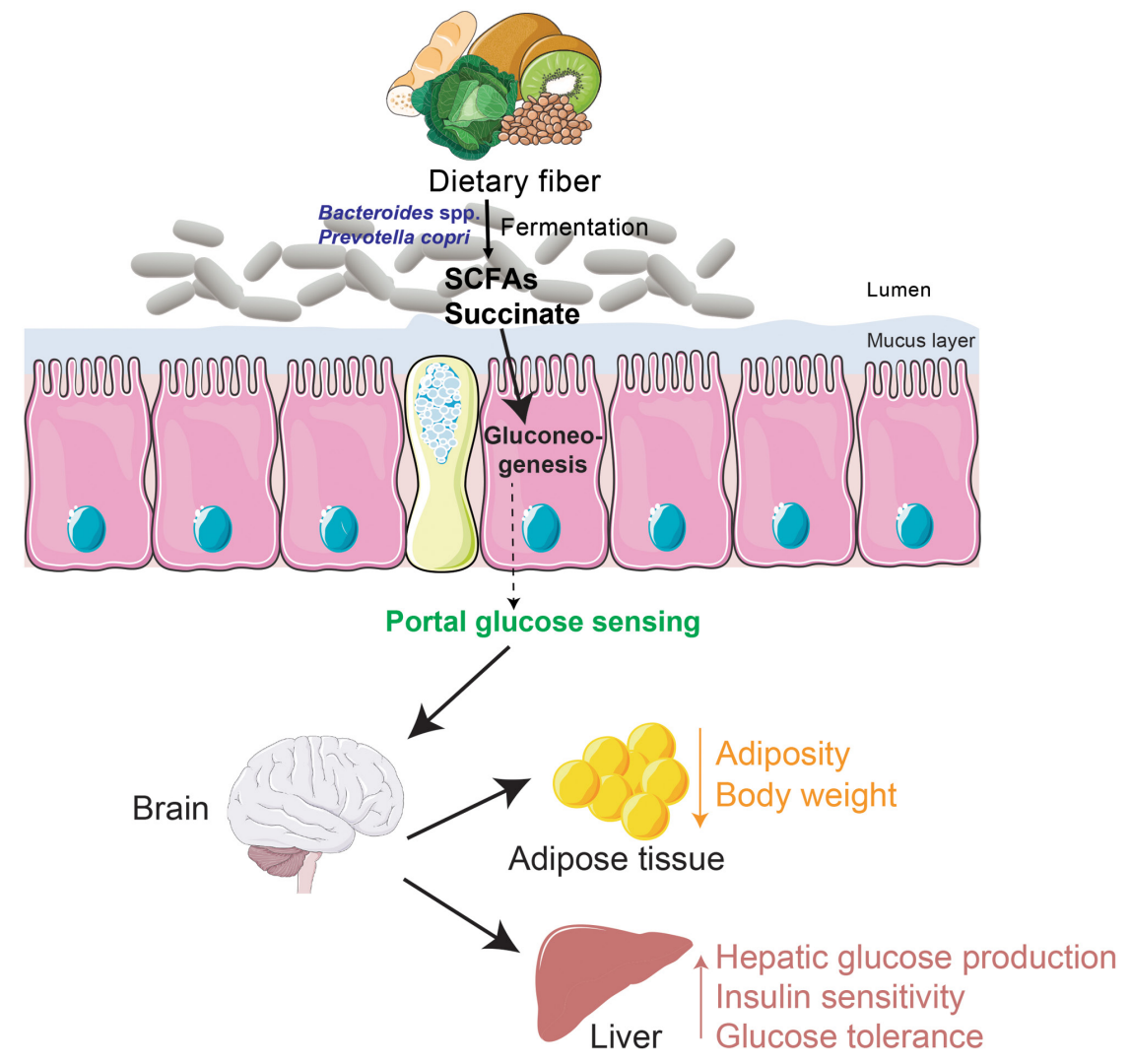

\section{Figure 1}

Sequence of events accounting for the metabolic benefits of dietary fiber on host metabolism.

\section{Succinate signaling to the brain: intestinal gluconeogenesis as a crucial link}

It is noteworthy that both propionate and succinate were previously described as efficient substrates for glucose production in the liver. This raised the hypothesis that, under in vivo conditions, succinate could be converted to glucose by the intestine, just as we previously showed for propionate (De Vadder et al. 2014). In fact, we showed that succinate produced from dietary fiber, as propionate, initiates the glucose signal to the brain and its metabolic benefits (Fig. 1), instead of reaching the liver to increase hepatic glucose production and peripheral glycemia.

Interestingly, while fiber feeding induced a shift in microbiota composition with an increase in Bacteroidetes and decrease in Firmicutes (David et al. 2014, De Vadder et al. 2014, 2016, Kovatcheva-Datchary et al. 2015); this was not the explanation of the metabolic benefits conferred on the host by fibers. Instead, the mechanisms explaining the benefits of fiber implied the aforementioned dialog with the host intestinal metabolism, resulting in the activation of IGN and its capacity of signaling to the brain. Accordingly, mice with an intestine-specific knockout of the G6pc gene (the major gene involved in glucose production) still exhibited an overweight and glucose-intolerant phenotype when fed a high-fat diet in conjunction with fiber or succinate (De Vadder et al. $2014,2016)$. Interestingly, this phenotype was observed despite changes in the microbiota composition similar to those in their wild-type counterparts. Therefore, it is the capacity of the host to use bacterial metabolites (especially propionate and succinate) to activate gutbrain glucose signaling and not the changes in microbiota composition, that drives the metabolic benefits of SCFAs and succinate.

\section{Declaration of interest}

The authors declare that there is no conflict of interest that could be perceived as prejudicing the impartiality of this review.

\section{Funding}

This work did not receive any specific grant from any funding agency in the public, commercial, or not-for-profit sector.

\section{Acknowledgements}

The authors wish to thank Fredrik Bäckhed and Petia Kovatcheva-Datchary for expert participation in their work in relation with the gut microbiota. 


\section{References}

Cani PD, Knauf C, Iglesias MA, Drucker DJ, Delzenne NM \& Burcelin R 2006 Improvement of glucose tolerance and hepatic insulin sensitivity by oligofructose requires a functional glucagon-like peptide 1 receptor. Diabetes 55 1484-1490. (https://doi.org/10.2337/db05-1360)

Cani PD, Neyrinck AM, Fava F, Knauf C, Burcelin RG, Tuohy KM, Gibson GR \& Delzenne NM 2007 Selective increases of bifidobacteria in gut microflora improve high-fat-diet-induced diabetes in mice through a mechanism associated with endotoxaemia. Diabetologia 50 2374-2383. (https://doi.org/10.1007/s00125-007-0791-0)

Cani PD, Possemiers S, Van de Wiele T, Guiot Y, Everard A, Rottier O, Geurts L, Naslain D, Neyrinck A, Lambert DM, et al. 2009 Changes in gut microbiota control inflammation in obese mice through a mechanism involving GLP-2-driven improvement of gut permeability. Gut 58 1091-1103. (https://doi.org/10.1136/gut.2008.165886)

Chambers ES, Viardot A, Psichas A, Morrison DJ, Murphy KG, ZacVarghese SEK, MacDougall K, Preston T, Tedford C, Finlayson GS, et al. 2015 Effects of targeted delivery of propionate to the human colon on appetite regulation, body weight maintenance and adiposity in overweight adults. Gut 64 1744-1754. (https://doi.org/10.1136/ gutjnl-2014-307913)

Cummings JH, Pomare EW, Branch WJ, Naylor CP \& Macfarlane GT 1987 Short chain fatty acids in human large intestine, portal, hepatic and venous blood. Gut 28 1221-1227. (https://doi.org/10.1136/ gut.28.10.1221)

David LA, Maurice CF, Carmody RN, Gootenberg DB, Button JE, Wolfe BE, Ling AV, Devlin AS, Varma Y, Fischbach MA, et al. 2014 Diet rapidly and reproducibly alters the human gut microbiome. Nature 505 559-563. (https://doi.org/10.1038/nature12820)

De Vadder F, Kovatcheva-Datchary P, Goncalves D, Vinera J, Zitoun C, Duchampt A, Bäckhed F \& Mithieux G 2014 Microbiota-generated metabolites promote metabolic benefits via gut-brain neural circuits. Cell 156 84-96. (https://doi.org/10.1016/j.cell.2013.12.016)

De Vadder F, Kovatcheva-Datchary P, Zitoun C, Duchampt A, Bäckhed F \& Mithieux G 2016 Microbiota-produced succinate improves glucose homeostasis via intestinal gluconeogenesis. Cell Metabolism 24 151-157. (https://doi.org/10.1016/j.cmet.2016.06.013)

Delaere F, Duchampt A, Mounien L, Seyer P, Duraffourd C, Zitoun C, Thorens B \& Mithieux G 2012 The role of sodium-coupled glucose co-transporter 3 in the satiety effect of portal glucose sensing. Molecular Metabolism 2 47-53. (https://doi.org/10.1016/j.molmet.2012.11.003)

Delzenne NM, Cani PD \& Neyrinck AM 2007 Modulation of glucagonlike peptide 1 and energy metabolism by inulin and oligofructose: experimental data. Journal of Nutrition 137 2547S-2551S.

Dewulf EM, Cani PD, Neyrinck AM, Possemiers S, Holle AV, Muccioli GG, Deldicque L, Bindels LB, Pachikian BD, Sohet FM, et al. 2011 Inulin-type fructans with prebiotic properties counteract GPR43 overexpression and PPAR $\gamma$-related adipogenesis in the white adipose tissue of high-fat diet-fed mice. Journal of Nutritional Biochemistry 22 712-722. (https://doi.org/10.1016/j.jnutbio.2010.05.009)

Everard A, Lazarevic V, Gaïa N, Johansson M, Ståhlman M, Backhed F, Delzenne NM, Schrenzel J, François P \& Cani PD 2014 Microbiome of prebiotic-treated mice reveals novel targets involved in host response during obesity. ISME Journal 8 2116-2130. (https://doi.org/10.1038/ ismej.2014.45)

Gao Z, Yin J, Zhang J, Ward RE, Martin RJ, Lefevre M, Cefalu WT \& Ye J 2009 Butyrate improves insulin sensitivity and increases energy expenditure in mice. Diabetes 58 1509-1517. (https://doi. org/10.2337/db08-1637)

Haraguchi T, Kayashima T, Okazaki Y, Inoue J, Mineo S, Matsubara K, Sakaguchi E, Yanaka N \& Kato N 2014 Cecal succinate elevated by some dietary polyphenols may inhibit colon cancer cell proliferation and angiogenesis. Journal of Agricultural and Food Chemistry 62 5589-5594. (https://doi.org/10.1021/jf501142k)

He W, Miao FJ-P, Lin DC-H, Schwandner RT, Wang Z, Gao J, Chen J-L, Tian H \& Ling L 2004 Citric acid cycle intermediates as ligands for orphan G-protein-coupled receptors. Nature 429 188-193. (https://doi.org/10.1038/nature02488)

Jakobsdottir G, Xu J, Molin G, Ahrné S \& Nyman M 2013 High-fat diet reduces the formation of butyrate, but increases succinate, inflammation, liver fat and cholesterol in rats, while dietary fibre counteracts these effects. PLoS ONE 8 e80476. (https://doi.org/10.1371/journal.pone.0080476)

Koh A, De Vadder F, Kovatcheva-Datchary P \& Bäckhed F 2016 From dietary fiber to host physiology: short-chain fatty acids as key bacterial metabolites. Cell 165 1332-1345. (https://doi.org/10.1016/j. cell.2016.05.041)

Kovatcheva-Datchary P, Nilsson A, Akrami R, Lee YS, De Vadder F, Arora T, Hallen A, Martens E, Björck I \& Bäckhed F 2015 Dietary fiber-induced improvement in glucose metabolism is associated with increased abundance of prevotella. Cell Metabolism 22 971-982. (https://doi.org/10.1016/j.cmet.2015.10.001)

Kushnir MM, Komaromy-Hiller G, Shushan B, Urry FM \& Roberts WL 2001 Analysis of dicarboxylic acids by tandem mass spectrometry. High-throughput quantitative measurement of methylmalonic acid in serum, plasma, and urine. Clinical Chemistry 47 1993-2002.

Lin HV, Frassetto A, Kowalik EJ Jr, Nawrocki AR, Lu MM, Kosinski JR, Hubert JA, Szeto D, Yao X, Forrest G, et al. 2012 Butyrate and propionate protect against diet-induced obesity and regulate gut hormones via free fatty acid receptor 3-independent mechanisms. PLOS ONE 7 e35240. (https://doi.org/10.1371/journal.pone.0035240)

Macfarlane S \& Macfarlane GT 2003 Regulation of short-chain fatty acid production. Proceedings of the Nutrition Society 62 67-72. (https://doi. org/10.1079/PNS2002207)

Meijer-Severs GJ \& van Santen E 1987 Short-chain fatty acids and succinate in feces of healthy human volunteers and their correlation with anaerobe cultural counts. Scandinavian Journal of Gastroenterology 22 672-676. (https://doi.org/10.3109/00365528709011141)

Miller TL \& Wolin MJ 1979 Fermentations by saccharolytic intestinal bacteria. American Journal of Clinical Nutrition 32 164-172.

Mithieux G, Misery P, Magnan C, Pillot B, Gautier-Stein A, Bernard C, Rajas F \& Zitoun C 2005 Portal sensing of intestinal gluconeogenesis is a mechanistic link in the diminution of food intake induced by diet protein. Cell Metabolism 2 321-329. (https://doi.org/10.1016/j. cmet.2005.09.010)

Rubic T, Lametschwandtner G, Jost S, Hinteregger S, Kund J, CarballidoPerrig N, Schwärzler C, Junt T, Voshol H, Meingassner JG, et al. 2008 Triggering the succinate receptor GPR91 on dendritic cells enhances immunity. Nature Immunology 9 1261-1269. (https://doi.org/10.1038/ ni.1657)

Sadagopan N, Li W, Roberds SL, Major T, Preston GM, Yu Y \& Tones MA 2007 Circulating succinate is elevated in rodent models of hypertension and metabolic disease. American Journal of Hypertension 20 1209-1215. (https://doi.org/10.1016/j.amjhyper.2007.05.010)

Soty M, Gautier-Stein A, Rajas F \& Mithieux G 2017 Gut-brain glucose signaling in energy homeostasis. Cell Metabolism 25 1231-1242. (https://doi.org/10.1016/j.cmet.2017.04.032)

Troy S, Soty M, Ribeiro L, Laval L, Migrenne S, Fioramonti X, Pillot B, Fauveau V, Aubert R, Viollet B, et al. 2008 Intestinal gluconeogenesis is a key factor for early metabolic changes after gastric bypass but not after gastric lap-band in mice. Cell Metabolism 8 201-211. (https://doi. org/10.1016/j.cmet.2008.08.008)

Zhong Y, Marungruang N, Fåk F \& Nyman M 2015 Effects of two whole-grain barley varieties on caecal SCFA, gut microbiota and plasma inflammatory markers in rats consuming low- and high-fat diets. British Journal of Nutrition 113 1558-1570. (https://doi.org/10.1017/S0007114515000793)

Received in final form 6 December 2017

Accepted 11 December 2017 http://joe.endocrinology-journals.org

https://doi.org/10.1530/JOE-17-0542 (c) 2018 Society for Endocrinology Published by Bioscientifica Ltd. Printed in Great Britain 